\title{
Induction and Suppression of an Autoimmune Disease by Oligomerized T Cell Epitopes: Enhanced In Vivo Potency of Encephalitogenic Peptides
}

\author{
By K irsten Falk, ${ }^{*}$ O laf R ötzschke, ${ }^{*}$ Laura Santambrogio, ${ }^{\ddagger}$ \\ $M$ artin E. D orf,, C elia B rosnan,,$\|$ and Jack L. Strominger ${ }^{\star \ddagger}$
}

\begin{abstract}
F rom the *D epartment of $M$ oleaular and $C$ ellular B iology, $\mathrm{H}$ arvard U niversity, $\mathrm{C}$ ambridge, $M$ assachusetts 02138 ; the $\mp D$ epartment of $C$ ancer I mmunology and $A I D S, D$ ana- $F$ arber $C$ ancer Institute, B oston, M assachusetts 02115 ; the ${ }^{\S} \mathrm{D}$ epartment of Pathology, $\mathrm{H}$ arvard M edical School, B oston, $M$ assachusetts 02115; and the UD epartment of Pathology, A lbert E instein C ollege of M ediane, B ronx, N ew York 10461
\end{abstract}

\begin{abstract}
T cell epitope peptides derived from proteolipid protein (PLP139-151) or myelin basic protein (M BP86-100) induce experimental autoimmune encephalomyelitis (EAE) in "susceptible" strains of mice (e.g., SJ L/J). In this study, we show that the encephalitogenic effect of these epitopes when injected subcutaneously in complete Freund's adjuvant was significantly enhanced if administered to the animal in a multimerized form as a T cell epitope oligomer (i.e., as multiple repeats of the peptide epitope, such as 16-mers). O ligomer-treated SJL/J mice developed EAE faster and showed a more severe progression of the disease than animals treated with peptide alone. In addition, haplotype-matched B10.S mice, "resistant" to EAE induction by peptide, on injection of 16-mers developed a severe form of EAE. Even more striking, however, was the dramatic suppression of incidence and severity of the disease, seen after single intravenous injections of only $50 \mu \mathrm{g}$ of the PLP139-151 16-mer, administered to SJL/J mice $7 \mathrm{~d}$ after the induction of the disease. Although relapse occurred at about day 45 , an additional injection several days before that maintained the suppression. Importantly, the specific suppres sive effect of oligomer treatment was also evident if EAE was induced with spinal cord homogenate instead of the single peptide antigen. By contrast, the PLP139-151 peptide accelerated rather than retarded the progression of disease.
\end{abstract}

Key words: apoptosis $\bullet$ anergy $\bullet$ high zone tolerance $\cdot$ experimental autoimmune encephalomyelitis $\bullet$ multimer

\section{Introduction}

$\mathrm{T}$ cell epitope oligomers are linear polypeptide chains, which consist of multiple copies of a T cell epitope. They contain up to 32 repeats of the epitope connected to each other by a flexible spacer sequence $(\mathrm{sp})^{1}$ of $\sim 13$ amino acids. Previously, oligomers (16-mers) of an epitope derived from the influenza virus hemagglutinin protein (H A306318) have been shown to induce an exceptionally strong

Address correspondence to Jack L. Strominger, D epartment of M olecular and Cellular Biology, $\mathrm{H}$ arvard U niversity, 7 Divinity Ave., Cambridge, M A 02138. Phone: 617-495-2733; Fax: 617-496-8351; E-mail: jlstrom@ fas.harvard.edu

${ }^{1} \mathrm{~A}$ bbreviations used in this paper: $E A E$, experimental autoimmune encephalomyelitis; $H$ A, influenza hemagglutinin protein; LN C, lymph node cell; M BP, myelin basic protein; M O G, myelin oligodendrocyte protein; PLP, proteolipid protein; sp, spacer sequence.
$\mathrm{CD} 4^{+} \mathrm{T}$ cell proliferative response in vitro (at almost 1,000-fold lower concentration than the peptide) (1). To evaluate whether oligomers can also act as stronger immunogens in vivo, experimental animal models were needed.

Experimental autoimmune encephalitis (EAE) is the best studied experimental animal model of a $T$ cell-mediated autoimmune disease. It serves as the animal model of human multiple sclerosis (2) and can be initiated by a subcutaneous injection of encephalitogenic peptides. In most cases, these peptides are "self-antigens" deriving from myelin proteins (3), such as proteolipid protein (PLP $[4,5]$ ), myelin basic protein (M BP $[6,7])$, or myelin oligodendrocyte protein (MOG [8]). These peptides, when associated to M H C class II molecules, are the target structure for autoreactive $C D 4^{+} \mathrm{T}$ cells. 
The extent of the pathological changes after the induction of the disease can be evaluated by scoring the clinical symptoms typical for EAE. This clinical score reflects the "encephalitogenicity" of the antigen and can be used to estimate its in vivo potency. How ever, not all mouse strains respond equally to a given encephalitogenic peptide antigen. Incidence rate and severity of the disease are strongly affected by the genotype of the recipient mouse. Primarily, the $\mathrm{H} 2$ haplotype dictates whether the strain is "permis sive" or "nonpermissive" for disease induction by the particular antigen, but in addition other genetic factors play a role ultimately determining whether a permissive strain is actually also "susceptible" (9). The secondary mechanisms underlying "susceptibility" and "resistance" are not known at the present time, but they appear to affect the overall sensitivity for the induction of an immune response. As a consequence, the induction of EAE in resistant strains, such as B10.S, requires the coinjection of proinflammatory cytokines such as IL-12 (10) or might require exceptionally strong immunogens.

The use of the EAE system for the evaluation of the in vivo potency also allows testing the potential of an antigen to suppress the immune response. In addition to therapeutic approaches using broadly immunosuppressing mechanisms such as the administration of antiinflammatory cytokines (11) or the neutralization of proinflammatory cytokines (12), other more targeted approaches were introduced to "silence" specifically the autoreactive $T$ cells. Most of these approaches aim at the induction of "high zone tolerance" (13), i.e., the induction of anergy (14) or the apoptotic elimination (15) of T cells by overstimulation after exposure to high concentrations of antigen. To achieve tolerance, the antigens have to be administered either by oral uptake (16-18), by intranasal deposition (19), or by intravenous or subcutaneous injection $(14,15,20$, 21). U sing these routes of administration, several antigens have already been used successfully in the EAE system to induce tolerance. The list includes peptides $(14,15,20)$ or peptide derivates modified by acylation (22) or amino acid substitution (23), but also proteins $(21,24)$ and proteinprotein (25) and immunoglobulin-protein chimeras (26). However, these experiments were usually carried out in transgenic animals, which express only the TCR specific for the peptide antigen $(15,20)$. Few reports exist in which "normal" nontransgenic mice were treated successfully with encephalitogenic self-peptides after the disease was already induced (27). In these cases, however, a relatively high internal level of the antigen had to be maintained by the frequent administration of high doses of the peptide.

In this study, we tested the efficiency of multimerized forms of the encephalitogenic T cell epitopes PLP139-151 (4) and M BP86-100 (7) on both the induction and suppression of EAE. The disease induction was tested with several mouse strains, including resistant B10.S mice in which the peptides were known to have no encephalitogenic effect. The effect on the suppression of the autoimmune disease was tested with normal SJL/J mice, not biased by the transgenic expression of a particular TCR .

\section{Materials and Methods}

A ntigens. For stability reasons, the residue Cys140 in the PLP139-151 epitope was substituted by Ser (a substitution that has no or little effect on the encephalitogenicty of the epitope [4]). The synthetic peptides PLP139-151(C 140S) (H SLGKW LGHPDKF), PLP139-151 (H CLGKW LGHPDKF), sp-PLP139-151 (C140S)-sp (GGGPG G HSGKW LGH PDKFGGPGGG), PLP178191(C 183S) (N TW T T SQ SIAFPSK), M BP86-100 (N PVVH FFKN IVTPR T), and M BP86-101 (N PVVH FFKN IVTPR TP) were produced by using standard solid phase F-moc chemistry and purchased from the Biopolymers Laboratory at the $\mathrm{H}$ arvard $\mathrm{M}$ edical School. All peptides were purified on a $\mathrm{C}_{4}$ - HPLC column (Vydac).

$O$ ligomerized $T$ cell epitopes were produced in Escherichia coli bacteria using recombinant techniques as described previously (1). In brief, double-stranded oligonucleotide units encoding the $T$ cell epitopes of the PLP139-151(C 140S) oligomers and M BP86-100 oligomers were generated by annealing two complementary strands of synthetic oligonucleotides (PLP139-151 (C 140S), + strand: 5'-TCACTCTCTGGGTAAATGGCTGGG TCACCCGGATAAAT TCGG, and - strand: 5'-GAATT T AT C CGGGT GAC C CAG C CATT TACC CAGAGAGTGACC; MBP86-100, + strand: 5'-CAACCCGGTTGTTCACTTCTTCAAAAACATCGTAACTCCGCGTACTGG, and - strand: 5'-AGTACGCGGAGTTACGATGTTTTTGAAGAAGTGAACAAGCGGGTTGCC). They were linked to the $\mathrm{N} \mathrm{H}_{2}$-terminal side of a spacer sequence (amino acid sequence of the $\mathrm{S} 3$ spacer: GGPGGGPGGGPGG) by cloning the oligonucleotides into the BsrDI site of a modified pC ITE vector (N ovagen), which contained the DN A encoding the S3 spacer (the construction of fulllength oligomeric DNA is described in reference 1 ). The same spacer was also used in M BP86-101 oligomers, which were provided by Dr. Shan C hung (Peptimmune, Inc., C ambridge, M A). The proteins were produced in T O P10 (pLyss) bacteria (Invitrogen) by using a pET 22b expression vector (N ovagen). The purification of the expressed protein was carried out using $\mathrm{Ni}^{2+}$. $\mathrm{NTA}$-agarose (Q iagen) by using a $\mathrm{H}$ is tag located at the $\mathrm{COOH}$ terminus of the constructs. Endotoxin and other impurities were removed from the polypeptide oligomers by separation on a reversed-phase $\mathrm{C}_{4}$ - $\mathrm{H}$ PLC column (Vydac).

Spinal cords from mice were isolated, homogenized, and lyophilized as described elsewhere (28).

$T$ C ell Lines and $C$ lones. The T cell lines SP/2, SP/3, PLP/a, and $P L P / C$ were generated and maintained as described previously (29). In brief, SJL mice were immunized subcutaneously with PLP139-151(C 140S) peptide emulsified in CFA. Lymph node cells (LN CS) were isolated on day 8-12 after immunization and initially stimulated with $50 \mu \mathrm{g} / \mathrm{ml}$ PLP139-151(C 140S) in the presence of $0.8-1.0 \%$ autologous mouse serum. The cultures were subsequently restimulated after $6 \mathrm{~d}$ and then every 2-3 wk with $10 \mu \mathrm{g} / \mathrm{ml}$ PLP139-151(C 140S) and irradiated syngeneic splenocytes (1,200 rad). They were expanded in DM EM (supplemented with $20 \mathrm{mM}$ glutamine, $1 \mathrm{mM}$ sodium pyruvate, 0.1 $\mathrm{mM}$ nonessential amino acids, $10 \mathrm{mM}$ Hepes buffer, 10\% FCS [Sigma $\mathrm{C}$ hemical $\mathrm{C}$ 0.]) plus $5-10 \%$ of a supernatant derived from concanavalin A-activated mouse splenocytes. The T cell line SP/ 178 was generated in the same way except that PLP178-191 was used instead of PLP139-151(C 140S). The T cell clones SP2.2A 8 and $8 \mathrm{~A} 1$ were obtained by limiting dilution of $T$ cell lines specific for the PLP139-151 antigen at a density of 0.5 cells/ well and maintained as described for the $T$ cell line. $T$ cell hybridomas $\mathrm{hPLP} / 1, \mathrm{hPLP} / \mathrm{a9} .4$, and hPLP/ 4 were generated by a polyethylene glycol fusion of the $T$ cell lines $P L P / a$ and $P L P / C$, respec- 
tively, with TCR - $\alpha / \beta^{-}$BW 1100 thymoma cells, selected in the presence of histone acetyltransferase (HAT) and cloned by limiting dilution as described previously (29).

Mice. SJL/J, PL/J, SW R, B10.S, B10, BALB/C, A.SW, and $A K R$ / J mice (6-8 wk of age) were purchased from The Jackson Laboratory and housed in the animal facility at $\mathrm{H}$ arvard $\mathrm{U}$ niversity or at $\mathrm{H}$ arvard M edical School. They were maintained in accordance with the Guidelines of the C ommittees on A nimals of $\mathrm{H}$ arvard $\mathrm{U}$ niversity, and the Committee on $\mathrm{C}$ are and $\mathrm{U}$ se of Laboratory Animal R esources, $N$ ational R esearch Council (Department of $\mathrm{H}$ ealth and $\mathrm{H}$ uman Services Publication 85-23, revised 1987).

In V itro A ssays. T cell proliferation assays were performed in 96-well round-bottomed plates using $5 \times 10^{5}$ irradiated $(1,200$ rad) splenocytes and $5 \times 10^{4} \mathrm{~T}$ cells per well in DMEM / 10\% FCS. After $48 \mathrm{~h}, 5 \mu \mathrm{Ci}\left[{ }^{3} \mathrm{H}\right.$ ] thymidine was added per well and the assay was harvested after $72 \mathrm{~h}$ and counted in a microbeta plate reader (W allac). The in vitro proliferation assays of primary LN C cultures were performed in the same way except that $5 \times$ $10^{5}$ nonirradiated LN C s were plated per well, [ ${ }^{3} \mathrm{H}$ ] thymidine was added after $72 \mathrm{~h}$, and the assay was harvested after $96 \mathrm{~h}$. The response of $T$ cell hybridomas ( $5 \times 10^{5}$ cells/ well) was tested with $5 \times 10^{5}$ splenocytes as target cells by collecting $30 \mu$ l of supernatant after $24 \mathrm{~h}$ for the determination of IL- 2 release in a proliferation assay with CTLL.

Induction of EAE. Mice were injected in the base of the tail and the nape of the neck with indicated amounts of peptide, $T$ cell epitope oligomer, or spinal cord homogenate together with $400 \mu \mathrm{g}$ M ycobacterium tuberculosis H 37R a (D ifco Laboratories) in an emulsion consisting of equal parts of PBS and CFA (Sigma Chemical $C_{0}$.). Each mouse was also injected intravenously with 200 ng of Pertussis toxin (List Biological Laboratories) on day 1 or on days 1 and 3 after immunization. $M$ ice were observed once or twice a day for clinical signs of EAE and scored on a scale of 1-5 according to the severity of the clinical signs as described previously (28).

Suppression of EAE by Intravenous Injections. EAE was induced in SJ L/J mice by the subcutaneous application of peptide antigens or homogenized mouse spinal cord emulsified in CFA followed by the injection of Pertussis toxin as described above. For the intravenous administration, the antigens were dissolved in PBS at a concentration of $0.5-1.0 \mathrm{mg} / \mathrm{ml}$ and injected into the tail vein at the dosage and time (day) indicated in the text.

$C$ ytokine $D$ etection. Samples of the supernatant from primary LNC cultures described above were taken after $96 \mathrm{~h}$. The amount of released IL-4 and IFN - $\gamma$ was determined in a sandwich ELISA using pairs of specific capture and biotinylated detection antibodies (PharM ingen) and streptavidin-horseradish peroxidase (Sigma Chemical C o.). The ELISA was developed with TMB (Kirkegaard \& Perry Laboratories) and measured at $450 \mathrm{~nm}$ using an M R X ELISA reader (Dynatech). IL-2, released by $T$ cell hybridomas, was determined by collecting $30-\mu$ samples of the supernatant $24 \mathrm{~h}$ after commencement of the $T$ cell assay by testing the samples in a secondary proliferation assay with IL-2-dependent CTLL cells. R ecombinant mIL-2 (Genzyme) was used as reference.

Immunohistochemistry. For assessment of inflammation, the brain and spinal cord were fixed in formalin, embedded in paraffin, and 7- $\mu \mathrm{m}$ sections were stained with hematoxylin and eosin according to standard pathological procedures. For assessment of demyelination, animals were perfused under anesthesia through the ascending aorta with $40 \mathrm{ml}$ of T rump's fixative (4\% paraformaldehyde, $1 \%$ glutaraldehyde in $0.1 \mathrm{M}$ phosphate buffer, $\mathrm{pH} 7.4$ ).
Slices of the brain and spinal cord were postfixed in cold $1 \%$ osmium tetroxide for $1 \mathrm{~h}$, dehydrated through a graded series of ethyl alcohol, and embedded in epoxy resin. 1- $\mu \mathrm{m}$ sections were stained with toluidine blue and examined by light microscopy in a blinded fashion.

\section{Results}

Proliferative Response of PLP139-151-spedic T C ells In $V$ itro. In a series of proliferation assays, the biological activity of a PLP139-151(C140S) 16-mer was tested with several different $\mathrm{T}$ cell lines and clones (generated as described in $M$ aterials and $M$ ethods; Fig. 1 A). Compared with the peptide, all T cell lines specific for the PLP139151 epitope responded better (lines SP/2, SP/3), or at least equally well, to the stimulation with the oligomer (lines $\mathrm{PLP} / \mathrm{a}, \mathrm{PLP} / \mathrm{c})$. No proliferation was induced by the PLP139-151(C 140S) 16-mer in the control line, SP/178, which is specific for PLP178-191. As had been established previously for another epitope (H A306-318; reference 1), the gain in sensitivity detected for some of these lines was significant. The T cell line SP2, for example, required $\sim 100$-fold lower concentrations of the 16-mer to induce a proliferation equivalent to that of the peptide. A more detailed picture of the proliferative response to the PLP139151(C 140S) 16-mer and peptide was obtained by analyzing single $T$ cell clones. In particular, the response of low-avidity $T$ cell clones improved to the 16-mer. As shown, some of these clones recognized 100-fold less 16-mer than peptide similar to the SP/ 2 line (SP2/2A8, hPLP/1), and for some clones (e.g., hPLP/a9.4) the specificity for 16-mer appeared even almost absolute. In contrast, other $\mathrm{T}$ cell clones (e.g., hPLP/c4) failed to efficiently recognize the 16-mer. For these clones, however, the failure to respond to the oligomer was found to be due to the extension of the actual $\mathrm{T}$ cell epitope by the spacer sequence, which presumably caused steric hindrance of the TCR-M HCantigen interaction (data not shown).

In the HA306-318 system, it has been shown that both the spacer length and the length of the oligomer (i.e., number of repetitive epitope units) have a profound effect on the outcome of the $T$ cell response. Testing the SP/ 2 line with a set of PLP oligomers revealed that also in the PLP system the oligomer length had a similar effect (Fig. 1 B, left). T he strongest response was triggered with a 16-mer, whereas the 4-mer, the shortest oligomer tested in this experiment, required 5-10 times higher concentrations. Similar results were also obtained with the $T$ cell clone $8 \mathrm{~A} 1$ (Fig. $1 \mathrm{~B}$, right). To determine the influence of the spacer on the $T$ cell recognition, this clone was also tested with a synthetic peptide, in which the actual core epitope was extended by parts of the spacer (sp-peptide-sp, see $M$ aterials and $M$ ethods; Fig.1 B, right). Although the multimerization of the epitope resulted in a significant increase in antigenicity $(>1$ log for the 4-mer and $>2$ logs for the 16mer), the extension of the epitope by the spacer sequence caused only a slight improvement in the proliferative response. The influence of oligomer length was not evident 
A
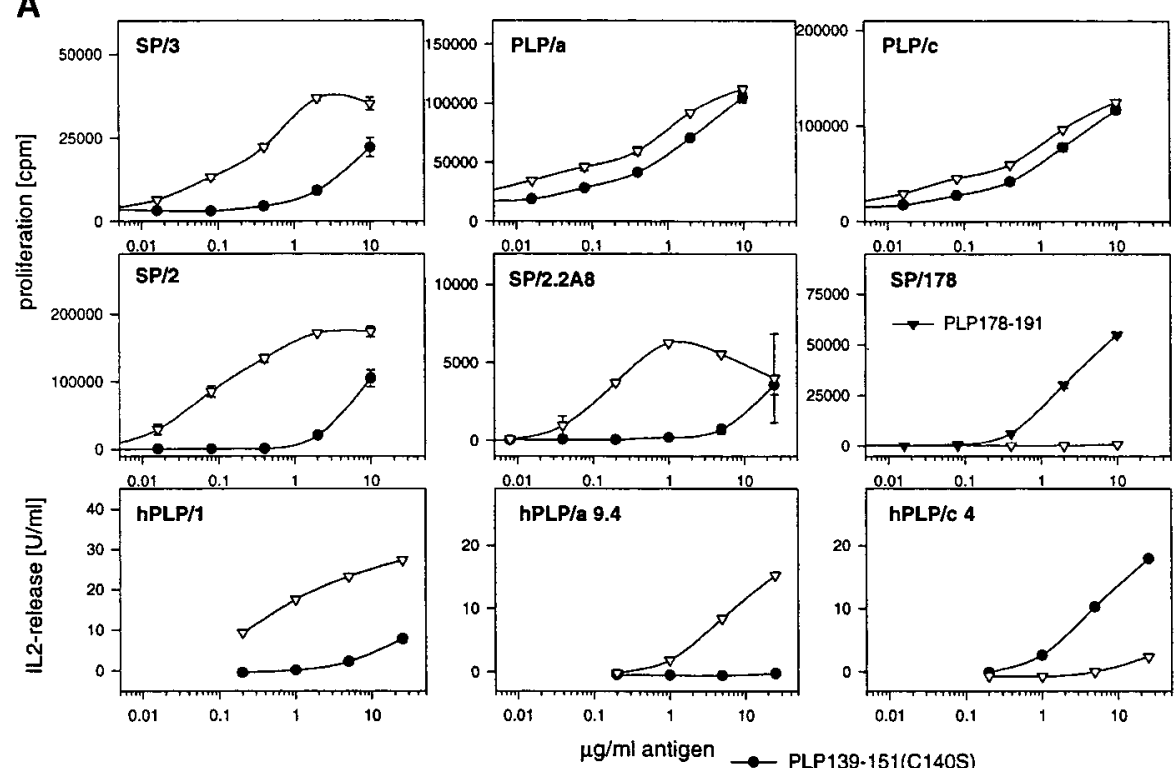

$\rightarrow-16 \mathrm{mer}$
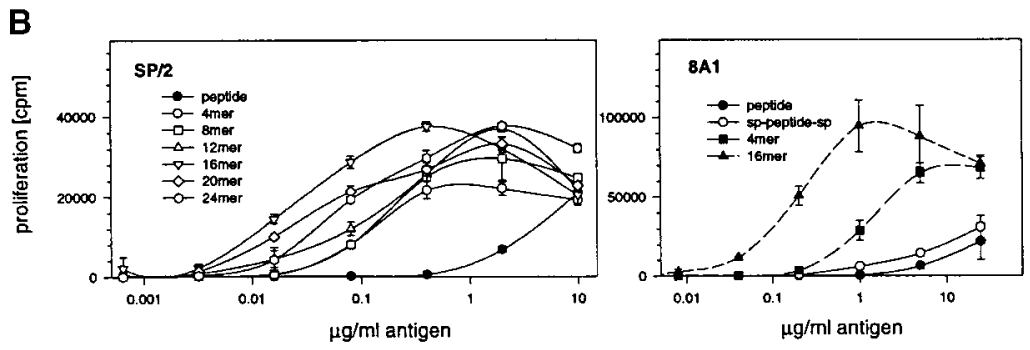

Figure 1. In vitro experiments with PLP139-151-specific T cells. (A) T cells raised against the PLP139-151(C 140S) peptide were challenged with titrated amounts of the PLP139-151(C 140S) peptide or the PLP139-151(C 140S) 16-mer. The specific response of the $T$ cell lines $S P / 3, P L P / a$, $\mathrm{PLP} / \mathrm{C}$, and $\mathrm{SP} / 2$, and of the $T$ cell clone $\mathrm{SP} / 2.2 \mathrm{~A} 8$ was measured in a proliferation assay. The response of the $T$ cell hybridomas $\mathrm{hPLP} / 1, \mathrm{hPLP} / \mathrm{a9} .4$, and hPLP/c4 was determined by their IL-2 release. Also shown is the proliferative response of the line SP/ 178, specific for PLP178-191. SJL/J splenocytes were used as target cells. (B) Doseresponse of PLP139-151-specific T cells to oligomers with an increasing number of repetitive epitope units. SP/2 T cells (left) were tested as described above with the PLP139-151(C 140S) peptide and a set of PLP139-151(C 140S) oligomers. The right panel shows the proliferative response of the clone 8A1. In addition to the the PLP139151(C 140S) peptide, the 4-mer, and the 16mer, this clone was also tested with a PLP139-151(C 140S) peptide containing the $\mathrm{NH}_{2-}$ and $\mathrm{COOH}$-terminal extensions of the spacer sequence (sp-peptide-sp: GGGPGG-PLP139-151[C 140S]-GGPGG G). in lines that did not show an improved response to the oligomers, and the trend was even reversed in clones that recognized oligomers only weakly (e.g., hPLP/c4, data not shown).

$T$ cells that responded most effectively to the stimulation with the 16-mer often show ed a reduced proliferation after exposure to the highest 16 -mer concentrations (10 or 50 $\mu \mathrm{g} / \mathrm{ml}$ ). For instance, a maximal proliferative response for the SP/ 2 (Fig. $1 \mathrm{~B}$, left) and SP/ 3 lines (Fig. $1 \mathrm{~A}$, top left) or the clone $8 \mathrm{~A} 1$ (Fig. $1 \mathrm{~B}$, right) or SP/2.2A 8 (Fig. $1 \mathrm{~A}$, middle) was triggered at a concentration of $\sim 0.5-1.0 \mu \mathrm{g} /$ $\mathrm{ml}$ 16-mer. The effect resembled high zone suppression and was not seen after incubation with the peptide.

Ex V ivo R esponse of P rimary T C ell C ultures. To determine whether the improved antigenicity, observed for some of the $T$ cells in vitro, would translate into an increased immunogenicity, mice were immunized with the PLP139-151(C 140S) peptide, with the 16-mer or, as a control, with adjuvant only (Fig. 2). Primary cell cultures, established from the draining LN s of the primed mice, were then challenged in vitro with titrated amounts of the PLP139-151(C 140S) peptide or the 16-mer. PLP139-151 is restricted by $I-A^{s}$, and mice from three different strains were used: SJL/J, which are permissive $\left(I-A^{s}\right)$ and EAE sus ceptible; B10.S, which are permissive (I-As) but EAE resis tant (30), and BALB/c, which, in principle, are EAE sus ceptible but are not permissive for this particular epitope $\left(I-A^{d}\right)$.

A specific proliferative response was only observed in the primary cultures derived from $\mathrm{SJ} \mathrm{L} / \mathrm{J}$ and B10.S mice treated with antigens (Fig. 2 A, panels 2, 3, 5, and 6). N o proliferation was detected in cultures established from BALB/C mice (panels 7-9) and in the control cultures derived from mice primed with adjuvant only (panels 1,4 , and 7). The strength of the T cell response was more vigorous in most cases if the primary culture was stimulated with the 16-mer. This was particularly evident in cultures generated from oligomer-primed mice. $\mathrm{H}$ ere, often $<100$-fold lower concentrations of 16-mer than of the peptide were effective (panels 3 and 6). The relative enhancement was more variable in the cultures derived from peptide-primed mice, and frequently these cultures responded equally well to the stimulation by peptide or 16-mer (e.g., Fig. 2 A, panel 2). Cultures derived from mice primed with the 16mer usually responded strongly to the 16-mer, but in most cases only relatively weakly to the stimulation with the monomeric peptide. The w eak response against the peptide might be explained by the predominant stimulation by the 16-mer of low-affinity clones (as suggested by the previous in vitro experiments), whereas the monomer is recognized 
A
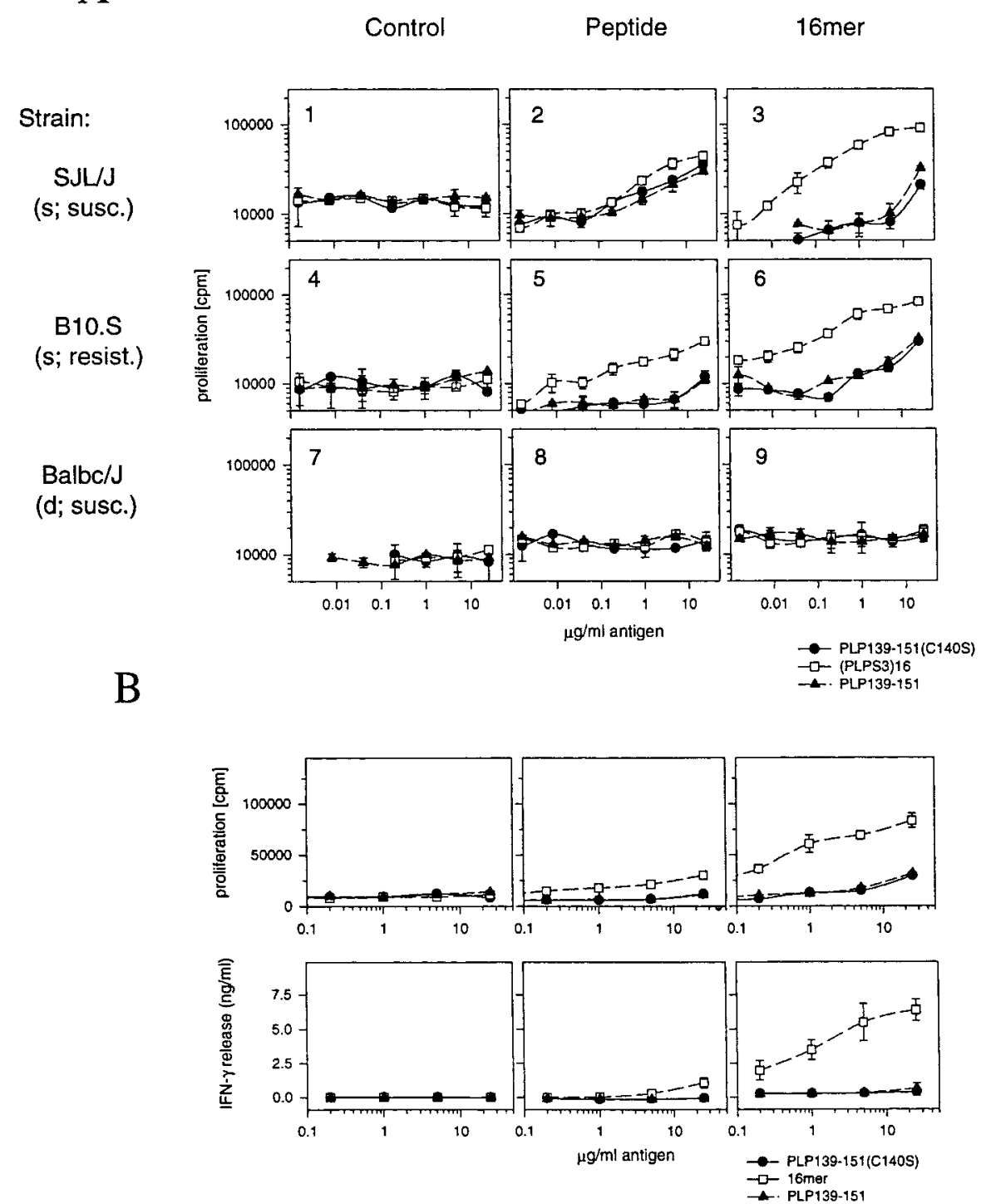

Figure 2. Ex vivo response of primary LN cultures. (A) Proliferative response of primary LN cultures of mice previously immunized with $50 \mu \mathrm{g}$ of either the PLP139-151(C 140S) peptide (panels 2,5 , and 8 ) or the 16-mer (panels 3, 6, and 9). Primary LN cultures were prepared from SJL/J mice (panels 1-3), B10.S mice (panels 4-6), and BALB/C mice (panels 7-9). The $\mathrm{H} 2$ haplotype and the EAE susceptibility (susc.)/ resistance (resist.) of the strains are indicated. The LN C s were isolated 7-12 d after the immunization and challenged in vitro by adding titrated amounts of the unsubstituted PLP139-151 peptide, the PLP139-151 (C 140S) peptide, or the PLP139-151(C 140S) 16-mer. As control, the response of cultures derived from mice treated with adjuvant only is shown (panels 1, 4, and 7). (B) Proliferative response (top) and the cytokine release (bottom) of primary LN cultures derived from B10.S mice. The amount of IFN - $\gamma$ was determined in supernatants taken $96 \mathrm{~h}$ after the start of the experiment. only by high-affinity clones. In any case, in susceptible SJL mice as well as in resistant B $10 . S$ mice, a strong and specific $T$ cell response could be generated by the immunization with the oligomer (panels 3 and 6). The priming with peptide, in particular in B10.S mice (panel 5), usually resulted in weakly responding primary cultures.

No IL-4 was detectable in any of these cultures (not shown). O $\mathrm{n}$ the other hand, IFN- $\gamma$ was found in the supernatants of all the primary cell cultures derived from antigen-primed mice, in particular after the challenge with the 16-mer. As an example, the IFN - $\gamma$ release of the cultures derived from B10.S mice is shown in Fig. 2 B. Although only relatively small amounts ( $\sim 1 \mathrm{ng} / \mathrm{ml}$ ) were detected in cultures generated from peptide-primed mice, $>6 \mathrm{ng} / \mathrm{ml}$ of IFN - $\gamma$ was measured in the supernatants derived from cultures of 16-mer-primed mice. The relatively high levels of IFN - $\gamma$ might be indicative of a preferred expansion of Th1 T cells after the immunization with the PLP 16-mer.
In V ivo Effect of PLP139-151 (C 140S) 0 ligomers. To determine whether the increased immunogenicity of the oligomer also results in an enhanced encephalitogenicity, a series of in vivo experiments was performed (Fig. 3). After the subcutaneous immunization of SJL/J mice with titrated amounts of either PLP139-151(C 140S) peptide or the 16mer, the mice were observed for the appearance of the typical clinical signs of EAE (Fig. 3 A). The score of the clinical symptoms revealed that SJ L/J mice were more sensitive to $E A E$ induction with the oligomer than with peptide. Compared with mice immunized with the peptide, they showed an earlier onset and a much more severe progression of the disease. At a dosage of $50 \mu \mathrm{g}$, the peptideprimed mice developed EAE on day 13 and had a maximal clinical score of 3.75 (incidence: $3 / 4$, mortality: $75 \%$ ). In contrast, the group primed with the 16-mer showed the first signs of the disease almost $4 \mathrm{~d}$ earlier (day 9) and reached the maximal clinical score of 5 (i.e., incidence: 4/ 4; 
A

SJL

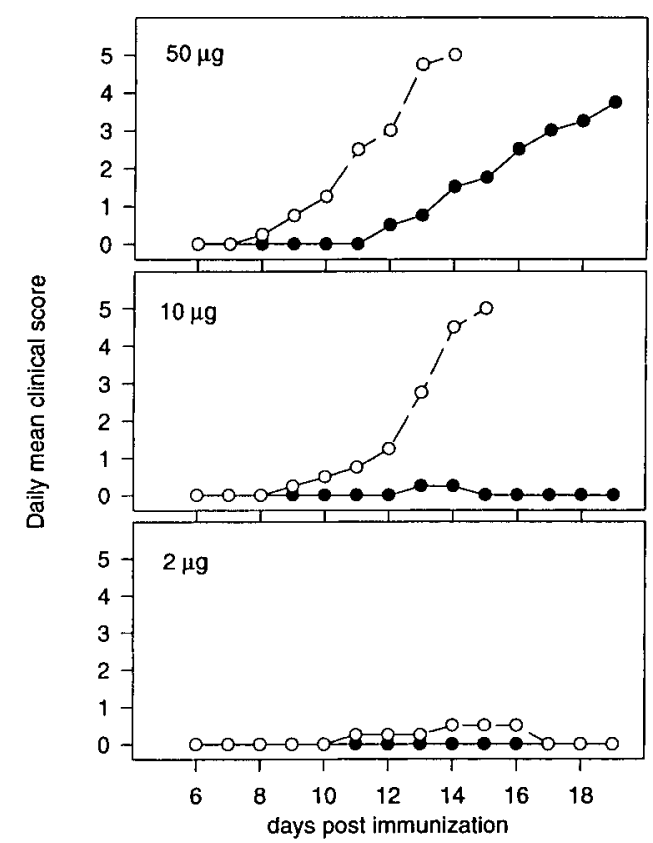

B

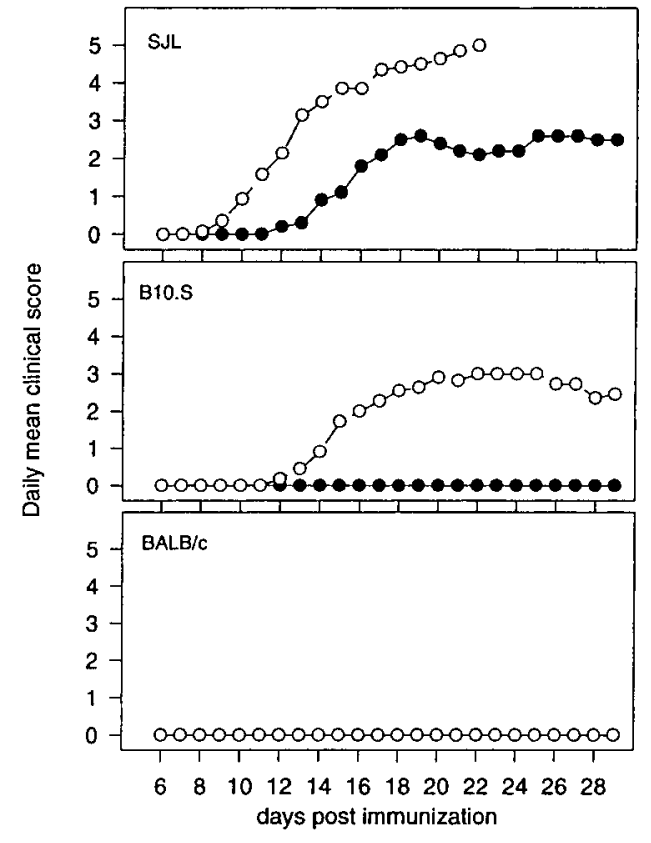

$\rightarrow-$ PLP139-151(C140S)
$\multimap-16 \mathrm{mer}$

Figure 3. Induction of EAE with PLP139-151(C 140S) oligomer. (A) D ose-response curves of peptide and 16-mer in susceptible SJL/J mice. EAE was induced in groups of four mice by subcutaneous injection of either $50 \mu \mathrm{g}$ (top), $10 \mu \mathrm{g}$ (middle), or $2 \mu \mathrm{g}$ (bottom) of the PLP139-151(C 140S) peptide or the 16-mer. The progression of the disease was determined on a daily basis by monitoring the mice for the appearance of clinical symptoms. The severity of the EAE is expressed in the mean score of these symptoms. Four mice per group were used. (B) EAE induction in susceptible and resistant strains. The encephalitogenic effect of 16-mer and peptide was tested with SJL/J mice (permissive/ susceptible, top), B 10.S mice (permissive/ resistant, middle), or BALB/c mice (nonpermissive/ susceptible, bottom). The mice were immunized subcutaneously with $50 \mu \mathrm{g}$ of either the PLP139-151(C 140S) peptide or the 16-mer. Filled circles of the peptide-treated BALB/c group are covered by the open symbol of the 16-mer-treated group. The clinical scores represent a compilation of several experiments using the following numbers of mice: SJL/J, 10 (peptide) and 14 (16-mer); B10.S, 9 (peptide) and 11 (16-mer); $\mathrm{BALB} / \mathrm{c}, 6$ (peptide) and 8 (16-mer).

mortality: 100\%). The trend also continued at lower dosages of the antigens. Although at the dosage of $10 \mu \mathrm{g}$ almost no clinical signs of disease were observed in the group primed with the peptide (incidence: 1/4; mean maximum score: 0.25$), 16$-mer-primed SJL mice developed a severe disease (incidence: 4/4; onset: day 11.5; mean maximum score: 5; mortality: 100\%). Even at the low est dosage tested $(2 \mu \mathrm{g})$, a mild form of EAE was still evident in the group treated with the 16-mer (incidence: 2/4; onset: day 13; mean maximum score: 0.5 ; mortality: $0 \%$ ). At this dosage, no effect was seen in the peptide group.

In the second part of this experiment, we addressed the question as to whether the oligomer could also induce EAE in resistant B10.S mice (Fig. 3 B). In accordance with previous reports (31), no clinical signs of the disease were observed in the B10.S group primed with the peptide. The 16-mer, in contrast, was also encephalitogenic in this strain (no effect with the peptide or the 16-mer was observed in the BALB/ c control group). The EAE was only sightly less severe than in SJL/J mice and, at a dosage of $50 \mu \mathrm{g}$, induced the disease with an incidence rate of $100 \%$. Compared with SJL/J mice, in B10.S mice the onset of the dis- ease was delayed by $\sim 3 \mathrm{~d}$ and resulted in a mean maximum score of 3.0. CN S immunohistochemistry performed on brain and spinal cord samples of the 16-mer-treated B10.S mice (Fig. 4) revealed an extensive submeningeal, perivascular, and parenchymal infiltration (Fig.4, panel 2), as well as demyelination (panel 4). In contrast, only some minor submeningeal infiltration (panel 1) and no demyelination (panel 3) was detectable in the samples from peptideprimed B 10.5 mice.

To demonstrate that induction of EAE was limited only to permissive strains, mouse strains with various $\mathrm{H} 2$ haplotypes were primed with either the peptide or the 16-mer (T able I). In all tested I-A $\mathrm{A}^{\mathrm{s}}$-expressing mouse strains, the treatment with the oligomer resulted in the induction of EAE. A.SW, for example, showed symptoms comparable to the ones described for $\mathrm{SJ} L / J$. N o clinical signs of the disease were observed in mice of the $b, d, k, q$, and $u$ haplotypes.

In V ivo E ffect of M B P 86-100 0 ligomers. To extend the study to other encephalitogenic $T$ cell epitopes, oligomers were tested in which the PLP139-151(C 140S) epitope was replaced by a $T$ cell epitope derived from the M BP protein 
PLP-peptide
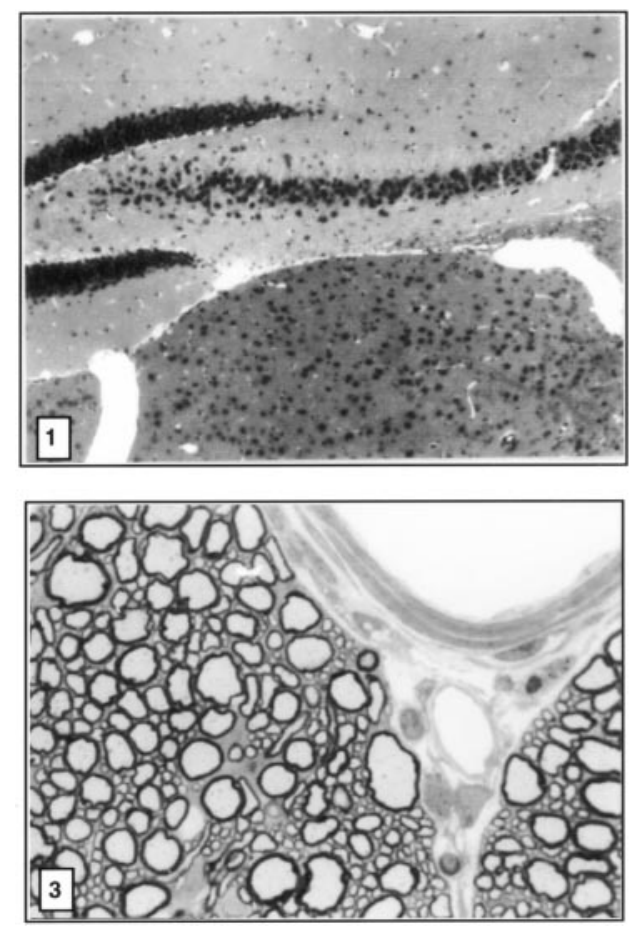

PLP-16mer
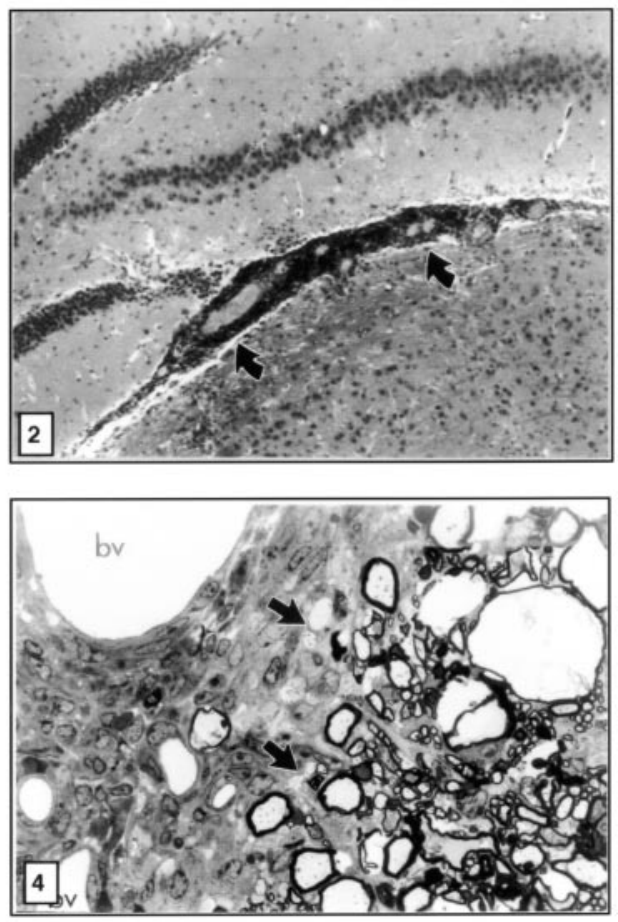

Figure 4. Pathological analysis of resistant B10.S mice after EAE induction with PLP139151(C 140S) oligomers. B10.S mice were sensitized subcutaneously with $50 \mu \mathrm{g}$ of either the PLP139-151(C 140S) peptide (panels 1 and 3) or the 16-mer (panels 2 and 4). $14 \mathrm{~d}$ after disease induction, the animals were perfused with fixative. Paraffinembedded sections of the brain were stained with hematoxylin and eosin to detect inflammatory infiltrates (panels 1 and 2, original magnifications $\times 350$ ), and plastic-embedded sections of the lumbar spinal cord were stained with toluidine blue to detect demyelination (panels 3 and 4 , original magnifications: $\times 750$ ). In animals sensitized with PLP139151(C 140S) peptide, no evidence of inflammation was detected in the brain (panel 1), and no inflammation or demyelination was noted within the spinal chord parenchyma (panel 3). In contrast, in the brains of animals sensitized with the 16-mer, dense accumulations of perivascular cells were observed around vessels overlying the anterior thalamus (arrows, panel 2). In the spinal cord, inflammatory cells were noted around blood vessels (bv), and inflammation, primary demyelination (arrows), and intramyelinic edema were detected within the anterior columns.
(M B P86-100). In vitro experiments indicated that, at least in the I-As system, M BP86-100 has a significantly lower antigenicity than PLP139-151. T cells, which show an improved response to the oligomer, seem to be less frequent in SJL mice and the ex vivo experiments revealed less im- pressive results compared with the PLP139-151 system (data not shown). H owever, to test if M BP86-100 oligomers showed some enhanced encephalitogenicity, the same series of in vivo experiments was performed as described previously for the PLP oligomers (Fig. 5).

Table I. C linical EA E in V arious Strains of M ice

\begin{tabular}{|c|c|c|c|c|c|c|c|c|c|c|c|}
\hline \multicolumn{2}{|c|}{ Mice } & \multicolumn{2}{|c|}{ Incidence of $E A E^{*}$} & \multicolumn{2}{|c|}{ Percent disease $\ddagger$} & \multicolumn{2}{|c|}{ Percent mortality§ } & \multicolumn{2}{|c|}{ M aximum mean scorell } & \multicolumn{2}{|c|}{ M ean day of onset\| } \\
\hline Strain & $\begin{array}{c}\mathrm{H} 2 \\
\text { haplotype }\end{array}$ & Peptide & 16-mer & Peptide & 16-mer & Peptide & 16-mer & Peptide & 16-mer & Peptide & 16-mer \\
\hline SJL/J & $\mathrm{s}$ & $17 / 20$ & $14 / 14$ & 85 & 100 & 40 & 100 & $3.1 \pm 2.0$ & $5.0 \pm 0.0$ & $14.0 \pm 1.5$ & $10.5 \pm 1.2$ \\
\hline A.SW & $\mathrm{s}$ & $5 / 6$ & $6 / 6$ & 83 & 100 & 66 & 100 & $3.5 \pm 2.3$ & $5.0 \pm 0.0$ & $13.8 \pm 2.0$ & $9.8 \pm 0.7$ \\
\hline B10.S & $\mathrm{s}$ & $0 / 9$ & $15 / 15$ & 0 & 100 & 0 & 33 & 0 & $3.1 \pm 1.5$ & - & $13.3 \pm 3.0$ \\
\hline $\mathrm{BALB} / \mathrm{C}$ & $d$ & $0 / 6$ & $0 / 8$ & 0 & 0 & 0 & 0 & 0 & 0 & - & - \\
\hline B10 & b & $0 / 4$ & $0 / 4$ & 0 & 0 & 0 & 0 & 0 & 0 & - & - \\
\hline$A K R / J$ & k & $0 / 4$ & $0 / 4$ & 0 & 0 & 0 & 0 & 0 & 0 & - & - \\
\hline SW R & $q$ & $0 / 4$ & $0 / 4$ & 0 & 0 & 0 & 0 & 0 & 0 & - & - \\
\hline $\mathrm{PL} / \mathrm{J}$ & u & $0 / 4$ & $0 / 4$ & 0 & 0 & 0 & 0 & 0 & 0 & - & - \\
\hline
\end{tabular}

EAE induction with PLP139-151(C 140S) oligomers in different strains of mice. M ice from various strains were immunized with $50 \mu g$ of either the PLP139-151(C 140S) 16-mer or the peptide as described in M aterials and $M$ ethods.

*V alues represent the number of mice with clinical signs of EAE as a fraction of the total number of immunized mice.

$\neq \vee$ alues represent the percentage of immunized mice with clinical signs of disease.

$\S$ Values representing the percentage of mortality refer to the total number of immunized mice.

$\| V$ alues representing mean day of onset and maximum mean clinical grade were scored as described in reference 28. 
SJL/J

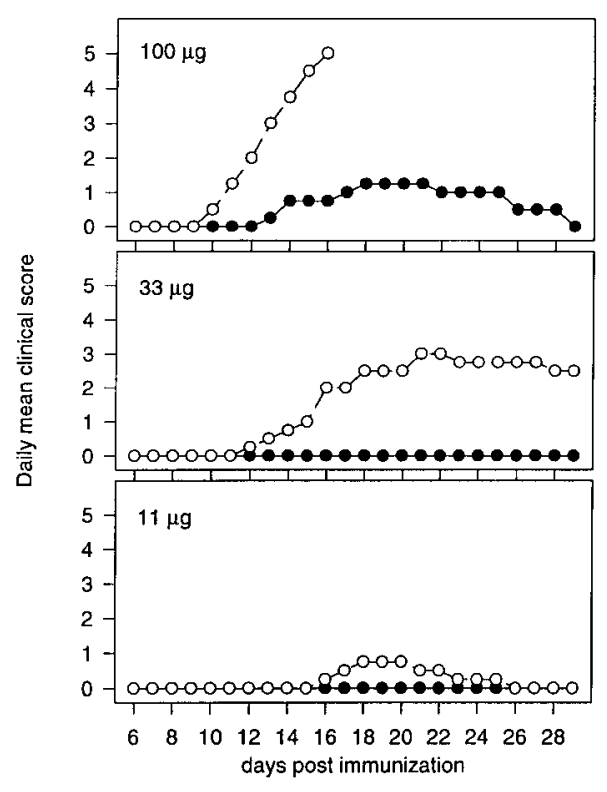

B10.S

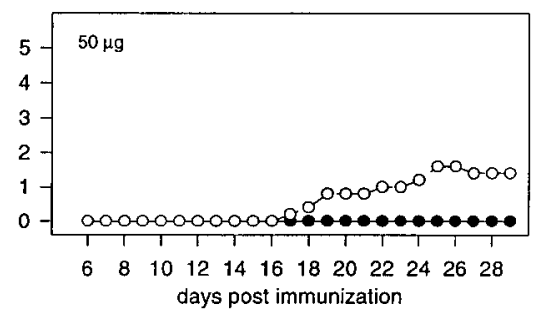

- MBP86- 100 peptide

-O- MBP86-100 16mer
The M BP86-100 16-mer was found to be a fairly potent inducer of EAE. Compared with the effect of the peptide, the application of the 16-mer resulted in an earlier onset and more severe progression of the disease. In a doseresponse study with SJL/J mice (Fig. 5, left), disease induction with the peptide was only observed after an injection of $100 \mu \mathrm{g}$, the highest dosage used in this experiment (incidence: $2 / 4$, onset: 13.5 , maximal mean score: 1.7 , mortality: $0 \%$ ). 0 ne third of this amount, $33 \mu \mathrm{g}$, was insufficient to trigger EAE. In contrast, the effect of the M BP86-100 16-mer was significantly stronger. At a dosage of $100 \mu \mathrm{g}$, all of the SJL mice treated with the 16-mer developed a fatal disease (incidence: 4/4, onset: 10.7, maximal mean score: 5.0 , mortality: 100\%). The encephalitogenic effect decreased at $33 \mu \mathrm{g}$ (incidence: 3/4, onset: 13.6, maximal mean score: 2.75 , mortality: $50 \%$ ) but was still evident at a dosage of $11 \mu \mathrm{g}$ where some cases of mild forms of EAE were observed (incidence: 2/4, onset: day 16.5, maximal mean score: 0.75 , mortality: $0 \%)$. Importantly, it was also possible to induce EAE in B10.S mice (Fig. 5, right). Compared with the PLP139-151 system, the effect of the M BP86-100 16mer was weaker but $50 \mu \mathrm{g}$ of the antigen was still sufficient to induce the disease in the majority of the tested animals (incidence: $3 / 5$; onset: day 18; maximal mean score: 1.6; mortality: $20 \%)$. The same treatment with the peptide did not cause any effect.

E ffect of Intravenous A dministration of 0 ligomers on the P rogression of EAE. To examine whether the oligomers could have a potential therapeutic impact in the suppression of $E A E$, mice were treated by intravenous injections i.v.-treatment prior to induction

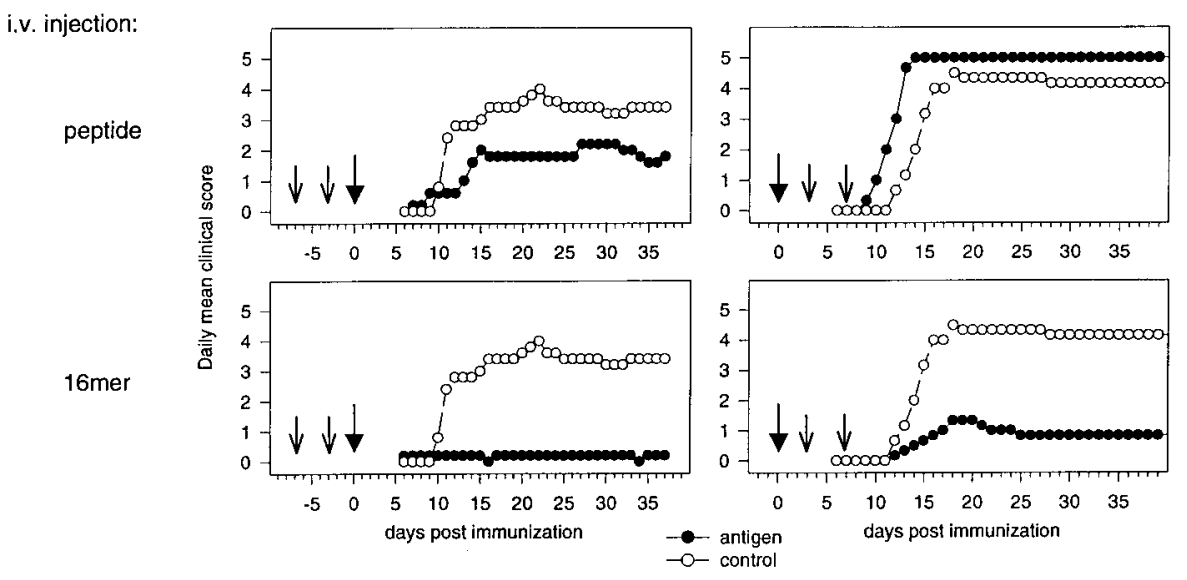

Figure 6. Suppression of EAE by intravenous injections of PLP139-151(C 140S) oligomers. SJ L/J mice were treated with intravenous injections of either PLP139151(C 140S) peptide (top) or the 16-mer (bottom) several days before (left) or after (right) disease induction. EAE was induced by a subcutaneous injection of $50 \mu \mathrm{g}$ PLP139-151(C 140S) peptide emulsified in CFA (filled arrowhead). The mice received the intravenous injections of peptide or 16mer on the day indicated by small open arrows. The daily mean clinical scores of the mice treated intravenously with antigens are shown in comparison to the score of control groups, which received mock intravenous injections of PBS instead of antigen.

Groups of five or six mice were used for the experiments. The incidence rates were determined as $5 / 5$ (control), $5 / 5$ (peptide), and $2 / 5$ ( 16 - mer) for the groups treated before the disease induction and as $6 / 6$ (control), $6 / 6$ (peptide), and 4/ 6 (16-mer) for the groups treated after the disease induction. 


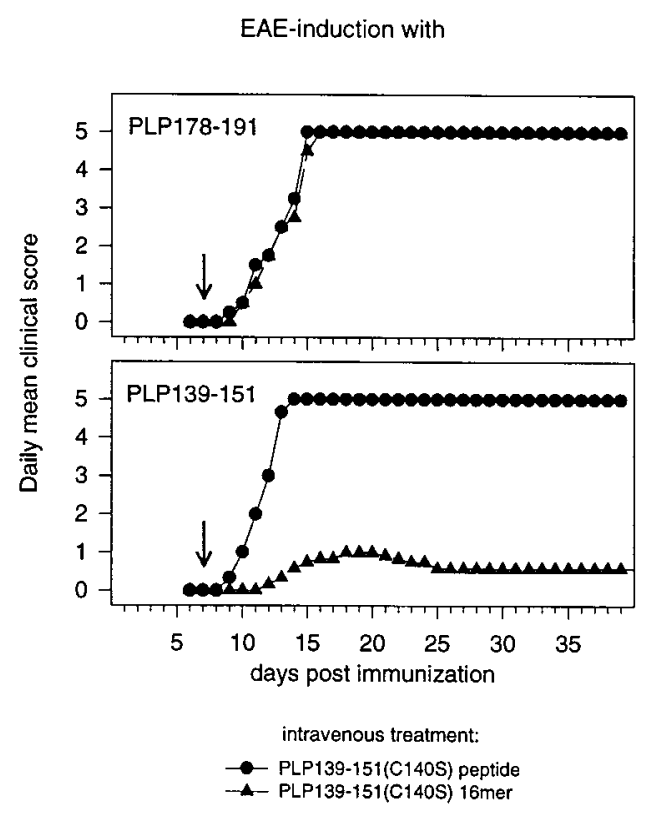

Figure 7. Specificity of EAE suppression by intravenous injections of PLP139-151(C140S) 16-mers. SJ L/J mice received intravenous injections of $50 \mu \mathrm{g}$ PLP139-151(C 140S) peptide or PLP139-151(C 140S) 16-mer $7 \mathrm{~d}$ after the induction of the disease by the subcutaneous injection of 50 $\mu g$ PLP178-191(C 183S) (top) or PLP139-151(C 140S) peptide (bottom). $G$ roups of six mice were used for the experiment. The incidence rates were determined as $6 / 6$ (peptide) and $6 / 6$ (16-mer) for the groups immunized with the PLP178-191(C 183S) peptide and as $6 / 6$ (peptide) and 4/ 6 (16mer) for the groups immunized with the PLP139-151(C 140S) peptide.

with PBS solutions of the PLP139-151(C 140S) antigens (Fig. 6). The experiment was carried out in SJL/J mice in which the disease was induced by the subcutaneous administration of $50 \mu \mathrm{g}$ PLP139-151(C 140S) peptide in CFA. The mice were treated either before (days -7 and -3 ; Fig. 6 , left) or after the disease induction (days 3 and 7; Fig. 6, right). The animals received the intravenous injections of peptide (top) or 16-mer (bottom) at a dosage of $50 \mu \mathrm{g}$, and control groups received a mock treatment with PBS.

The intravenous treatment with the 16-mer almost completely prevented the development of the disease (Fig. 6 , bottom). W ith the treatment before the disease induction (bottom left), four of the five mice did not show any clinical signs, and only one mouse developed a very mild form of EAE (score of 1 , resulting in a mean score of 0.2 ). Importantly, the effect of the 16-mer was also evident if the treatment was done several days after the induction of the disease (bottom right). T wo injections of $50 \mu \mathrm{g}$ were sufficient to reduce the maximal mean clinical score to a value of 1.3 compared with a score of 4.5 in the control group. After the initial attack, which peaked at day 19 , most of the mice returned within $6 \mathrm{~d}$ to a condition virtually free of any clinical symptoms. In contrast to the treatment with the 16-mer, the effect of the peptide was far less dramatic. Although peptide treatment before the disease induction (Fig. 6, top left) resulted at least in some reduction of the severity of the EAE progression (maximal mean score of

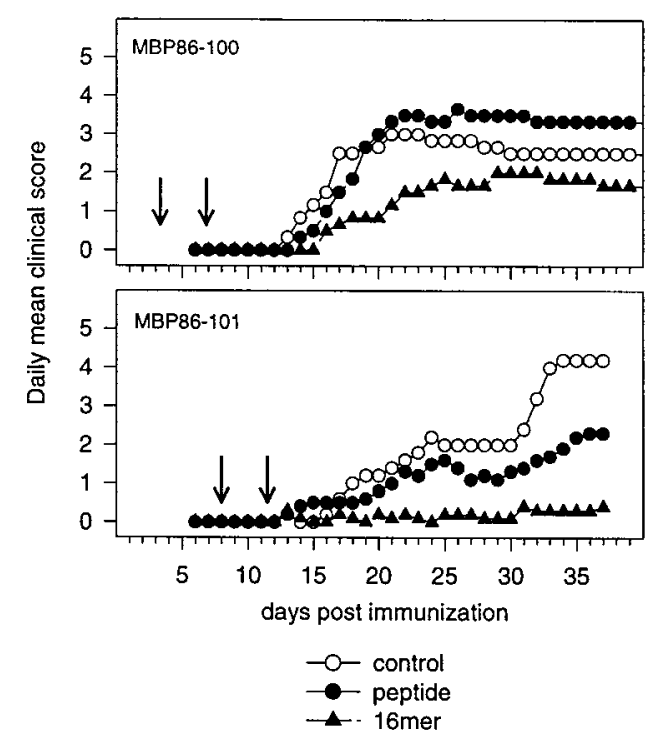

Figure 8. Suppression of EAE by intravenous injections of oligomers containing the M BP86-100 epitope. SJL/J mice were treated with intravenous injections of M BP86-100 (top) or M BP86-101 (bottom). EAE was induced on day 0 by the subcutaneous injection of $100 \mu \mathrm{g} \mathrm{M} \mathrm{BP86-}$ 100 or $200 \mu \mathrm{g}$ M BP86-101 peptide, respectively. The mice were treated intravenously with peptide, 16-mer, or PBS at the indicated time points (arrows) and received dosages of $100 \mu \mathrm{g}$ of the M BP86-100 or $200 \mu \mathrm{g}$ of the M BP86-101 antigens. Groups of 5-10 mice were used for the experiment. The incidence rates were determined as 5/ 6 (control), 6/ 6 (peptide), and 4/6 (16-mer) for the groups primed and treated with the M BP86-100 epitope and as 5/ 5 (control), 9/ 10 (peptide), and 4/ 10 (16mer) for the groups primed and treated with the M BP86-101 epitope.

2.2), the treatment after disease induction (top right) resulted in acceleration of disease progression. The onset shifted by almost $2 \mathrm{~d}$, and a maximal mean score of 5 (i.e., $100 \%$ mortality) was reached earlier, by day 14 .

The effect of peptide treatment on enhancing instead of suppressing the disease progression could not be overcome by an increase in dosage. Even when $250 \mu \mathrm{g}$ was administered to the animals, no reverse in the trend was apparent (data not shown). $\mathrm{O}$ the other hand, with the 16-mer a single injection of $50 \mu \mathrm{g}$ on day 7 was found to be sufficient to produce a strong suppression (Fig. 7, bottom). At this time point, only very little submeningeal, perivascular infiltration was evident in brain sections taken from SJL/J mice immunized with the peptide (data not shown). H owever, the effect of the 16-mer was found to be highly specific, and no suppression was evident if the disease was induced with the PLP178-191 peptide (Fig. 7, top) instead of the PLP139-151 peptide (Fig. 7, bottom). Similar results were also obtained with MBP antigens containing the epitopes M BP86-100 and M BP86-101 (Fig. 8). O nly a relatively modest suppression was observed after an injection of $100 \mu \mathrm{g}$ of M BP86-100 16-mer on days 3 and 7 (triangles, top). The effect was greatly enhanced after using a 16-mer containing the more antigenic epitope M BP86101 at an increased dosage $(200 \mu \mathrm{g})$ on days 8 and 12 . Also in the M BP system, the intravenous treatment with peptides had little or no effect (filled circles). 

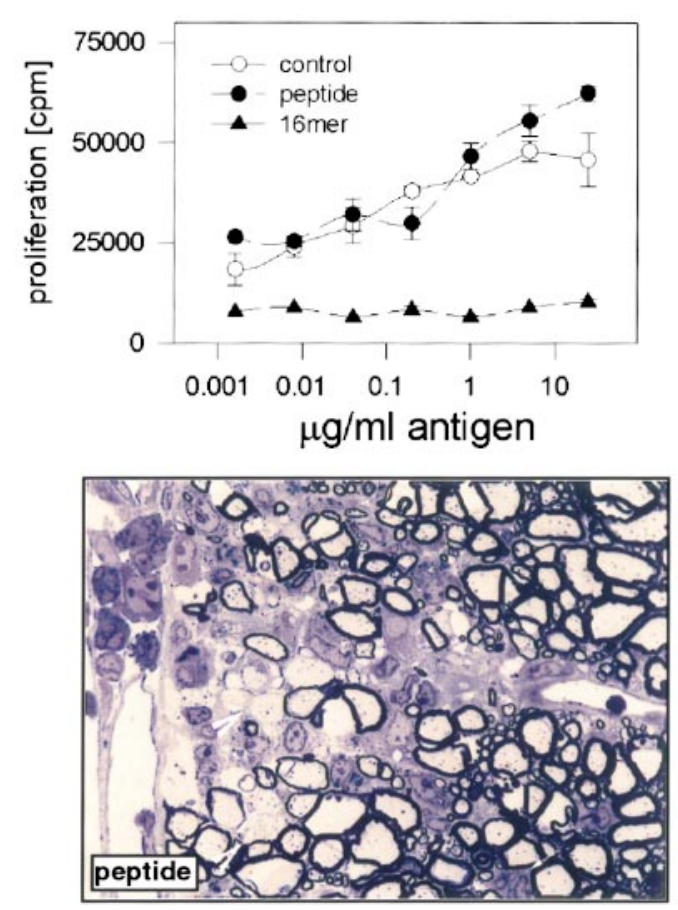
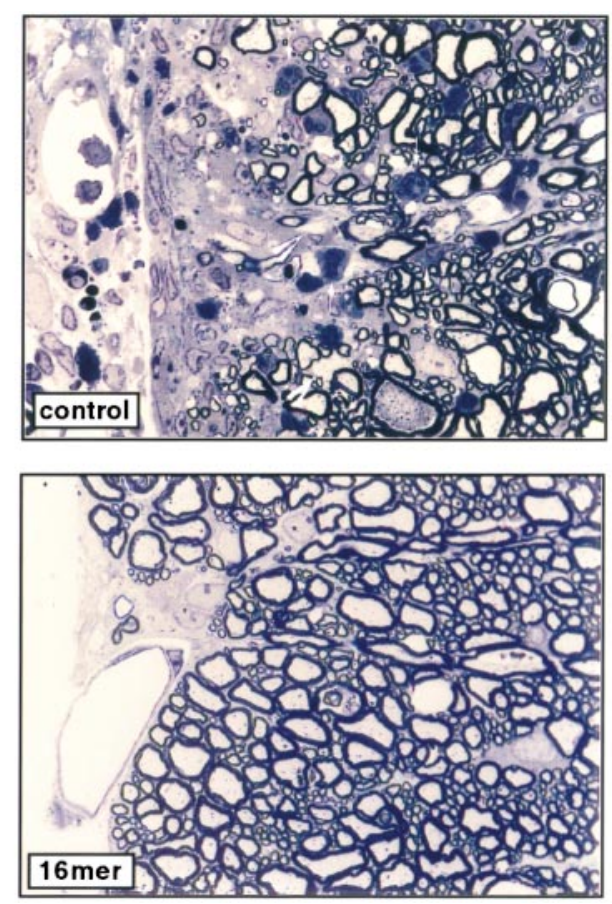

Figure 9. Pathological analysis and lymphocyte proliferative response after intravenous treatment with PLP139-151(C140S) 16-mer. EAE was induced in SJL/J mice with PLP139-151 (C 140S) peptide. $7 \mathrm{~d}$ later, the mice received intravenous injections of either $50 \mu \mathrm{g}$ PLP139-151 (C140S) peptide, PLP139-151 (C140S) 16-mer, or mock injections of PBS. 7 d later (day 14), LN s were removed to test the ex vivo response, and the mice were perfused with Trump's fixative before the removal of the spinal cord for the histological analysis of disease. The ex vivo response of primary LNCS of peptide, 16-mer-, and mock-treated mice is shown in the top left panel. LN C s were challenged in a proliferation assay with titrated amounts of PLP139-151(C 140S) 16-mer (top left). The proliferation assay was performed essentially as described in the legend to Fig. 2. The other panels show the histochemical image of $1-\mu \mathrm{m}$ thick plastic-embedded tissue stained with toluidine blue. The samples derived from the mock-treated control animal (top right) and from the peptidetreated mouse (bottom left) show submeningeal lesions typical of EAE (meninges located on the left of the panels). The meningeal vessels were inflamed, and numerous inflammatory cells were detected within the cord parenchyma (arrows). In tissues from control animals, large numbers of polymorphonuclear cells were evident (small arrows). D emyelinated axons (arrowheads) were present within the inflamed area of the cord. In contrast, in the sample derived from the 16-mer-treated mouse (bottom right), the meningeal vessels were not inflamed and the cord parenchyma showed no evidence of inflammation or demyelination. O riginal magnifications: $\times 500$.

Ex vivo experiments with primary LN cultures (LN Cs) further indicated that in mice treated with the PLP139151 (C 140S) 16-mer, the specific response against this antigen was either reduced, or, as shown in the top left panel of Fig. 9 (triangles), completely absent. In contrast, the antigen-specific response of LN C s from peptide-treated mice (filled circles) was similar to that of the control group (open circles). This silencing of the $T$ cell response, presumably due to apoptosis or anergy induction, was found to be antigen specific, since the $T$ cell proliferation triggered by staphylococcal enterotoxin A or B was unaffected (not shown). The histological analysis of the tissues taken from the mice revealed interesting differences in the pathology between the three groups. In the mock-treated animals (Fig. 9, top right), the lesions showed prominent demyelination (arrowheads) in the presence of an inflammatory infiltrate that contained numerous polymorphonuclear cells (small arrows). In the peptide- treated animals (bottom left), inflammation and demyelination were also evident and the lesions contained mostly mononuclear cells. Importantly, however, in cord tissue from animals tolerized with the 16mer no inflammation or demyelination was noted (bottom right), although a low level of inflammation was still present in the brains of these animals (data not shown).

L ong-T erm E ffects, C ontrol of R elapse, and Inducion with Spinal C ord. W ithout the 16-mer treatment, in most cases the mice did not recover from the initial attack, whereas with the 16-mer treatment the disease was suppressed for at least $40 \mathrm{~d}$. Long-term studies revealed that after that period the mice started to relapse (Fig. $10 \mathrm{~A}$, top). The time frame between the acute episode and the relapse is consistent with the appearance of a new wave of autoreactive PLP139-151-specific $T$ cells from the thymus. Although during the relapsing phase the $T$ cell response reportedly becomes more heterogeneous due to epitope spreading (32-34), an additional intravenous injection with the PLP139-151(C 140S) 16-mer on day 40 was still effective in further preventing the appearance of clinical symptoms (Fig. $10 \mathrm{~A}$, bottom). A similar suppression was also achieved when the disease was triggered by broadly stimulating spinal cord homogenate instead of a single epitope (Fig. 10 B). Compared with mice induced with the PLP139-151 peptide, the treatment was sightly less effective, but a strong suppression was also evident after induction with spinal cord (Fig. $10 \mathrm{~B}$, top). Previous reports indicated that PLP139-151 is the dominant epitope in SJL/J mice after immunization with spinal cord homogenate (35). By using a 16-mer with this immunodominant epitope the maximal daily mean score of the initial attack was reduced to only 1.7 compared with 4.5 for the control group, and a complete recovery of the 16-mer-treated mice was observed by day 34 before the mice started to relapse. A second dose, administered on day 12 , greatly enhanced the suppressive effect (Fig. $10 \mathrm{~B}$, bottom). In this experiment, the mice treated twice with the 16-mer remained free of clinical symptoms for $>60 \mathrm{~d}$. 
A

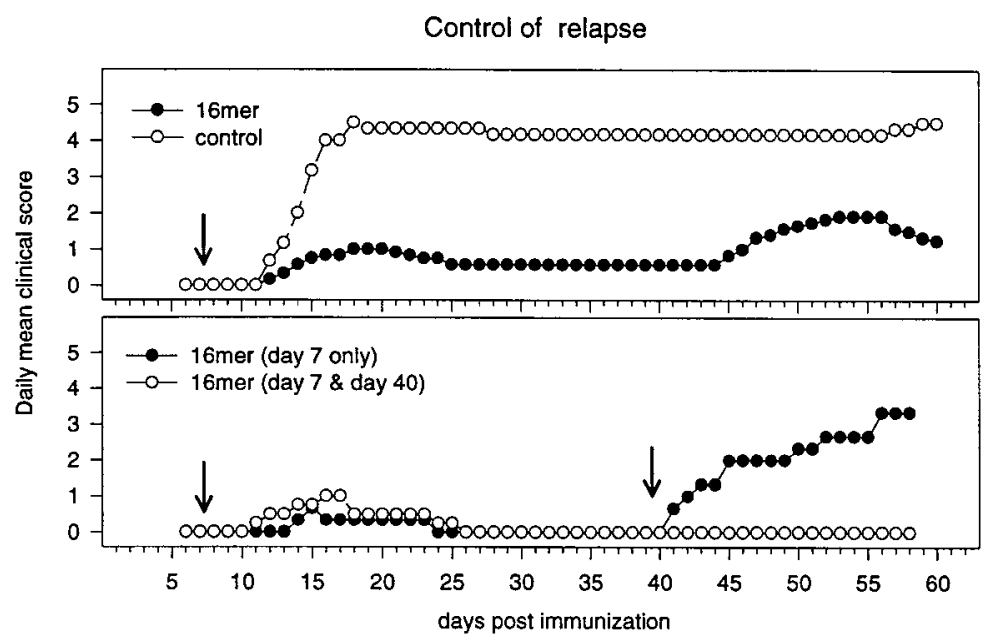

B

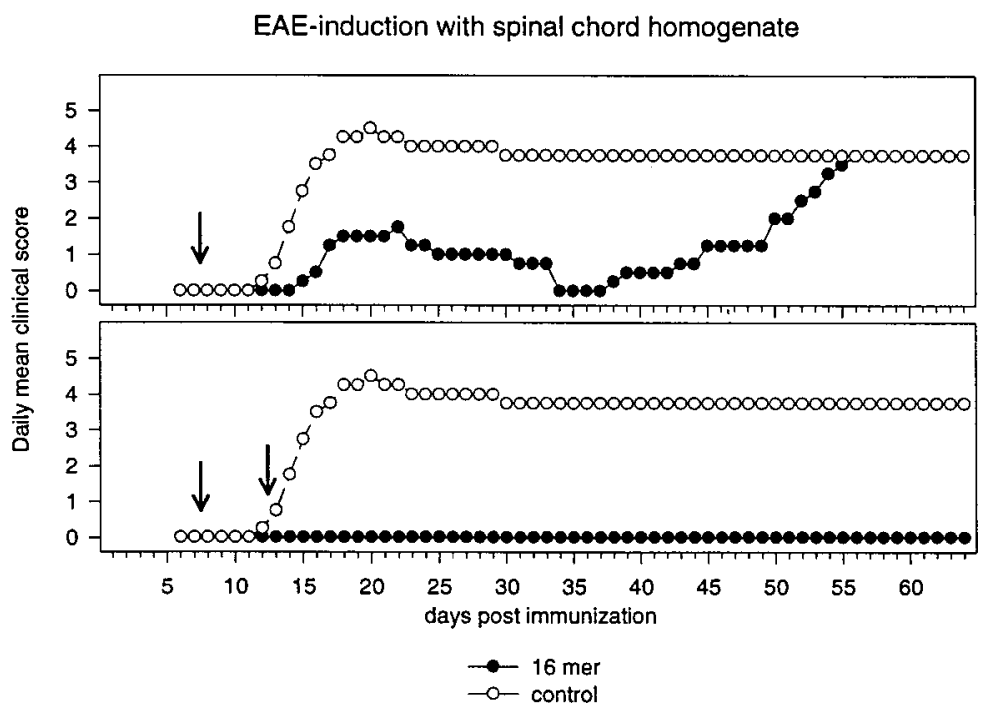

Figure 10. Control of relapse and effect of intrave nous treatment with PLP139-151(C 140S) 16-mer after $\mathrm{EAE}$ induction with spinal cord homogenate. (A) Long-term effect of the treatment with PLP 16-mer and prevention of relapse. The top panel shows an experiment in which $\mathrm{SJ} L / J$ mice received only a single intravenous dosage of $50 \mu \mathrm{g}$ PLP139- 151 (C 140S) 16mer on day 7. The clinical score is plotted in comparison to the score of a control group treated with PBS only. In the experiment shown in the bottom panel, mice either received only the single dosage of $50 \mu \mathrm{g}$ 16-mer on day 7 or w ere treated again the same way on day 40 . Groups of four mice were used for the experiments, and the disease was induced by subcutaneous administration of PLP139-151(C 140S) peptide. (B) Treatment of EAE with PLP139-151(C 140S) 16-mer after induction with spinal cord homogenate. The experiment was carried out as described above except that $4 \mathrm{mg}$ of spinal cord homogenate instead of the PLP peptide was used for the disease induction. The SJL/J mice received intravenous injections of $50 \mu \mathrm{g}$ 16-mer either on day 8 (top) or on days 8 and 12 (bottom). The control group was treated with mock injections of PBS. Groups of five mice were used for this experiment.

\section{Discussion}

The trimolecular interaction of TCR-peptide-MHC represents the structural basis of the immune response. Several attempts have already been made to modulate this interaction with the intent to enhance the response to a vaccine (36-38), and multimerization or oligomerization is another approach in this direction. Soluble multivalent peptide-MHC complexes were previously shown to smultaneously engage multiple TCR s resulting in complexes, which are significantly more stable than the respective monomeric complex $(39,40)$. Furthermore, the TCR cross-linking promoted by this interaction initiates signal transduction and triggers the activation cascade of the $T$ cell, which significantly lowers the threshold for the activation (41). In addition, the use of multimerized $T$ cell epitopes can produce similar effects. The multimerized antigens, which were designed to form multivalent arrays of peptide-M HC complexes on the surface of the APC $s$, can show, in some cases, great enhancement in the antigenicity of the epitope.

The oligomerized encephalitogenic antigens presented in this study were not only more effective in the stimulation of antigen-specific $T$ cells in vitro, but also induced stronger primary $T$ cell responses in vivo. The priming of mice with these antigens resulted in the manifestation of very severe forms of $E A E$, evident even in resistant strains. Earlier studies suggested that the failure of resistant B10.S mice to develop EAE is caused by a paucity of high-affinity autoreactive $T$ cells $(42,43)$. Since the oligomerized antigens were particularly effective in the stimulation of low-avidity $T$ cells, the increased encephalitogenicity might be attributable to the induction of a broader $T$ cell response by the recruitment of a larger number of $T$ cell clones. Part of this might be due to a potentially reduced need for costimulatory signals. Studies with tetrameric peptide-M HC com- 
plexes indicated that at least for these tetramers the influence of CD4 on the binding is diminished (40). In addition, the activation of the APC s by M HC cross-linking $(1,44)$ and the "proteinization" of the epitope could contribute to the effect. An increased stability of the epitope, altered routes of antigen presentation, and a more effective $T$ cell stimulation by an activated APC might be relevant particularly for the increase in antigenicity in vivo. A nother factor might be the strong enhancement of a Th1-type T cell response. Autoreactive $\mathrm{CD} 4^{+} \mathrm{T}$ cells of the Th1 type are the driving force in $T$ cell-mediated autoimmune diseases, and a preferred activation of this $T$ cell subset would certainly promote the progression of EAE. In fact, a recent study (45) indicated that the resistance of B10.S mice might be due to a failure of antigen-specific $C D 4^{+} \mathrm{T}$ cells to upregulate $C D 40$ ligand. This failure abrogates the release of $\mathrm{IL}-12$ and subsequently affects the expression level of the $\beta 2$ subunit of IL-12R, a receptor crucial in controlling Th1 lineage commitment. At this point, how ever, it is not clear whether the enhancement of encephalitogenicity is actually caused by a selective activation of Thl T cells.

$M$ aybe even more important than the improved stimulation is the effect of oligomerized antigens if administered intravenously on the suppression of the autoimmune dis ease. $\mathrm{H}$ igh zone tolerance as a mechanism of $\mathrm{T}$ cell tolerization has been known for some time (13), but its practicality has been limited by the requirement of extremely high antigen (peptide, protein) levels. The enhanced antigenicity of multimerized antigens might make this approach more feasible. A drastic decrease in incidence and severity of EAE was achieved after a single intravenous treatment with a relatively low dosage of $50 \mu \mathrm{g}$ per mouse. In vitro experiments with HA306-318 oligomers and human influenza virus-specific $T$ cells indicated that the underlying mechanism is most likely the apoptotic elimination of the "overstimulated" autoreactive T cell (data not shown). The reduction in the antigen-specific ex vivo response of mice treated with encephalitogenic oligomers and the long period of protection after treatment are consistent and suggest that this mechanism is also responsible for the specific suppression in the EAE system. Importantly, the suppression was also observed at the onset of the relapsing phase and after disease induction with spinal cord homogenate. The effectiveness of the oligomers in these situations together with the observation that a fraction of the autoreactive $T$ cell population actually fails to respond to the multimerized antigen suggests that, in addition to the antigen-specific suicidal T cell elimination, "bystander" effects contribute to the high zone suppression.

Thus, oligomerized antigens can be effective in the induction and suppression of the immune response. In addition to their use as vaccines for the stimulation of preventive pathogen-specific $T$ cell responses, they might be particularly valuable for the immunotherapy of tumors. M ost chronic autoimmune diseases are mediated by $C D 4^{+}$ $\mathrm{T}$ cells, and the recruitment of autoreactive $\mathrm{CD} 4^{+} \mathrm{T}$ cells specific for tumor antigens (46) might permit the develop- ment of a similar situation, with the immune response directed towards the specific destruction of the transformed tissue. Furthermore, the striking effects of multimeric T cell epitopes in high zone applications might provide a new stimulus for the use of autoantigens in therapies aimed at the specific suppression of acute or chronic autoimmune states.

W e are very grateful to S. Jah and M .L. W ong for excellent technical assistance, and to $\mathrm{K}$. W ormstadt for animal maintenance. In particular, we thank M. Lenardo for thoroughly reviewing the manuscript and for his helpful comments.

This research was supported by $\mathrm{N}$ ational Institutes of $\mathrm{H}$ ealth grants 5R 35-CA47554 and N 01-AI45198.

Submitted: 25 A ugust 1999

R evised: 5 N ovember 1999

A ccepted: 8 D ecember 1999

\section{References}

1. R ötzschke, O ., K. Falk, and J.L. Strominger. 1997. Superactivation of an immune response triggered by oligomerized $\mathrm{T}$ cell epitopes. Proc N atl. A cad. Sa. U SA. 94:14642-14647.

2. M artin, R ., and H. M cFarland. 1996. Experimental immunotherapies for multiple sclerosis. Springer Semin. Immunopathol. 18:1-24.

3. M cFarlin, D.E., S.E. Blank, R.F. Kibler, S. M cK neally, and R. Shapira. 1973. Experimental allergic encephalomyelitis in the rat: response to encephalitogenic proteins and peptides. Science. 179:478-480.

4. Tuohy, V.K., Z. Lu, R.A. Sobel, R.A. Laursen, and M.B. Lees. 1989. I dentification of an encephalitogenic determinant of myelin proteolipid protein for SJL mice. J. Immunol. 142: 1523-1527.

5. Greer, J.M., V.K. Kuchroo, R.A. Sobel, and M.B. Lees. 1992. Identification and characterization of a second encephalitogenic determinant of myelin proteolipid protein (residues 178-191) for SJL mice. J. Immunol. 149:783-788.

6. Zamvil, S.S., D.J. M itchell, A.C. M oore, K. Kitamura, L. Steinman, and J.B. R othbard. 1986. T - cell epitope of the autoantigen myelin basic protein that induces encephalomyelitis. N ature. 324:258-260.

7. Kono, D.H., J.L. U rban, S.J. Horvath, D.G. Ando, R.A. Saavedra, and L. Hood. 1988. T wo minor determinants of myelin basic protein induce experimental allergic encephalomyelitis in SJL/J mice. J. Exp. M ed. 168:213-227.

8. M endel, I., N . Kerlero de R osbo, and A. Ben-N un. 1995. A myelin oligodendrocyte glycoprotein peptide induces typical chronic experimental autoimmune encephalomyelitis in $\mathrm{H}-2 \mathrm{~b}$ mice: fine specificity and $T$ cell receptor $V$ beta expression of encephalitogenic T cells. E ur. J. Immunol. 25:1951-1959.

9. Butterfield, R .J., E.P. Blankenhorn, R .J. R oper, J.F. Zachary, R.W . D oerge, J. Sudw eeks, J. R ose, and C. T euscher. 1999. Genetic analysis of disease subtypes and sexual dimorphisms in mouse experimental allergic encephalomyelitis $(E A E)$ : relapsing/remitting and monophasic remitting/nonrelapsing $\mathrm{EAE}$ are immunogenetically distinct. J. Immunol. 162:3096-3102.

10. Segal, B.M ., and E.M. Shevach. 1996. IL-12 unmasks latent autoimmune disease in resistant mice. J. Exp. M ed. 184:771-775.

11. Santambrogio, L., G.M. Crisi, J. Leu, G.M. Hochwald, T. 
R yan, and G.J. Thorbecke. 1995. T olerogenic forms of autoantigens and cytokines in the induction of resistance to experimental allergic encephalomyelitis. J. N euroimmunol. 58: 211-222.

12. Leonard, J.P., K.E. W aldburger, and S.J. G oldman. 1995. Prevention of experimental autoimmune encephalomyelitis by antibodies against interleukin 12. J. Exp. M ed. 181:381-386.

13. Diener, E., and M . Feldmann. 1972. M echanisms at the cellular level during induction of high zone tolerance in vitro. C ell. Immunol. 5:130-136.

14. Gaur, A., B. W iers, A. Liu, J. R othbard, and C.G. Fathman. 1992. A melioration of autoimmune encephalomyelitis by myelin basic protein synthetic peptide-induced anergy. Sdence. 258:1491-1494.

15. C ritchfield, J.M., M.K. R acke, J.C. Zuniga-Pflucker, B. C annella, C.S. R aine, J. Goverman, and M .J. Lenardo. 1994. $T$ cell deletion in high antigen dose therapy of autoimmune encephalomyelitis. Science. 263:1139-1143.

16. Whitacre, C.C., I.E. Gienapp, A. M eyer, K.L. Cox, and N. Javed. 1996. T reatment of autoimmune disease by oral tolerance to autoantigens. C lin. Immunol. Immunopathol. 80:S31-S39.

17. Kennedy, K.J., W.S. Smith, S.D. M iller, and W .J. Karpus. 1997. Induction of antigen-specific tolerance for the treatment of ongoing, relapsing autoimmune encephalomyelitis: a comparison between oral and peripheral tolerance. J. I mmunol. 159:1036-1044.

18. W einer, H.L. 1997. O ral tolerance: immune mechanisms and treatment of autoimmune diseases. Immunol. T oday. 18:335-343.

19. Liu, J.Q., X.F. Bai, F.D. Shi, B.G. Xiao, H.L. Li, M. Levi, M. M ustafa, B. Wahren, and H. Link. 1998. Inhibition of experimental autoimmune encephalomyelitis in Lewis rats by nasal administration of encephalitogenic M BP peptides: synergistic effects of M BP 68-86 and 87-99. Int. Immunol. 10: $1139-1148$.

20. T onegawa, S.M .S. 1997. Tolerance induction and autoimmune encephalomyelitis amelioration after administration of myelin basic protein-derived peptide. J. Exp. M ed. 186:507-515.

21. Staykova, M.A., R.D. Simmons, and D.O. Willenborg. 1997. Infusion of soluble myelin basic protein protects longterm against induction of experimental autoimmune encephalomyelitis. Immunol. C ell Biol. 75:54-64.

22. St. Louis, J., X.M. Zhang, E. Heber-Katz, S. U niyal, D. R obbinson, B. Singh, and G.H. Strejan. 1999. Tolerance induction by acylated peptides effect on encephalitogenic $T$ cell lines. J. A utoimmun. 12:177-189.

23. Brocke, S., K. Gijbels, M. Allegretta, I. Ferber, C. Piercy, T. Blankenstein, R. M artin, U. U tz, N. Karin, and D. M itchell. 1996. Treatment of experimental encephalomyelitis with a peptide analogue of myelin basic protein [published erratum at 392:630]. N ature. 379:343-346.

24. Elliott, E.A., R. C ofiell, J.A. W ilkins, C.S. R aine, L.A. M a tis, and J.P. Mueller. 1997. Immune tolerance mediated by recombinant proteolipid protein prevents experimental autoimmune encephalomyelitis. J. N euroimmunol. 79:1-11.

25. Elliott, E.A., H.I. M CFarland, S.H. N ye, R . C ofiell, T.M . W ilson, J.A. Wilkins, S.P. Squinto, L.A. M atis, and J.P. M ueller. 1996. T reatment of experimental encephal omyelitis with a novel chimeric fusion protein of myelin basic protein and proteolipid protein. J. C lin. Invest. 98:1602-1612.

26. M in, B., K.L. Legge, C. Pack, and H. Zaghouani. 1998. $\mathrm{N}$ eonatal exposure to a self-peptide-immunoglobulin chimera circumvents the use of adjuvant and confers resistance to autoimmune disease by a novel mechanism involving in- terleukin 4 lymph node deviation and interferon $\gamma$-mediated splenic anergy. J. Exp. M ed. 188:2007-2017.

27. Leadbetter, E.A., C.R. Bourque, B. Devaux, C.D. O Ison, G.H. Sunshine, S. H irani, B.P. W allner, D.E. Smilek, and M .P. H app. 1998. Experimental autoimmune encephalomyelitis induced with a combination of myelin basic protein and myelin oligodendrocyte glycoprotein is ameliorated by administration of a single myelin basic protein peptide. J. Immunol. 161:504-512.

28. Santambrogio, L., G.M. H ochwald, B. Saxena, C.H. Leu, J.E. M artz, J.A. Carlino, N.H. R uddle, M .A. Palladino, L.I. Gold, and G.J. Thorbecke. 1993. Studies on the mechanisms by which transforming growth factor-beta (TGF-beta) protects against allergic encephalomyelitis. Antagonism between T GFbeta and tumor necrosis factor. J. Immunol. 151:1116-1127.

29. Santambrogio, L., M.B. Lees, and R.A. Sobel. 1998. Altered peptide ligand modulation of experimental allergic encephalomyelitis immune responses within the C N S. J. N euroimmunol. 81:1-13.

30. Lublin, F.D., R.L. Knobler, P.C. Doherty, and R . Korngold. 1986. R elapsing experimental allergic encephalomyelitis in radiation bone marrow chimeras between high and low susceptible strains of mice. C lin. Exp. Immunol. 66:491-496.

31. Encinas, J.A., M .B. Lees, R .A. Sobel, C. Symonowicz, J.M . Greer, C.L. Shovlin, H.L. W einer, C.E. Seidman, J.G. Seidman, and V.K. Kuchroo. 1996. Genetic analysis of susceptibility to experimental autoimmune encephalomyelitis in a cross between SJL/J and B10.S mice. J. Immunol. 157: 2186-2192.

32. Lehmann, P.V., T. Forsthuber, A. M iller, and E.E. Sercarz. 1992. Spreading of T-cell autoimmunity to cryptic determinants of an autoantigen. $N$ ature. 358:155-157.

33. M CR ae, B.L., C.L. Vanderlugt, M.C. Dal C anto, and S.D. Miller. 1995. Functional evidence for epitope spreading in the relapsing pathology of experimental autoimmune encephalomyelitis. J. Exp. M ed. 182:75-85.

34. T uohy, V.K., M. Y u, L. Y in, J.A. Kawczak, J.M. Johnson, P.M. M athisen, B. W einstock-Guttman, and R .P. Kinkel. 1998. The epitope spreading cascade during progression of experimental autoimmune encephalomyelitis and multiple sclerosis. Immunol. R ev. 164:93-100.

35. Whitham, R.H., D.N. Bourdette, G.A. Hashim, R.M. H erndon, R.C. Ilg, A.A. Vandenbark, and H . O ffner. 1991. Lymphocytes from SJL/J mice immunized with spinal cord respond selectively to a peptide of proteolipid protein and transfer relapsing demyelinating experimental autoimmune encephalomyelitis. J. Immunol. 146:101-107.

36. Corradin, G., and S. Demotz. 1997. Peptide-M HC complexes assembled following multiple pathways: an opportunity for the design of vaccines and therapeutic molecules. H um. Immunol. 54:137-147.

37. Barber, B.H . 1997. The immunotargeting approach to adjuvant-independent subunit vaccine design. Semin. Immunol. 9:293-301.

38. U rban, R.G., R .M . C hicz, and M .L. H edley. 1997. The discovery and use of HLA-associated epitopes as drugs. C rit. Rev. Immunol. 17:387-397.

39. Altman, J.D., P.A.H. M oss, P.J.R. Goulder, D.H. Barouch, M .G. M CH eyzer-W illiams, J.I. Bell, A.J. M CM ichael, and M .M. D avis. 1996. Phenotypic analysis of antigen- specific T lymphocytes [published erratum at 280:1821]. Science. 274:94-96.

40. Crawford, F., H. K ozono, J. W hite, P. M arrack, and J. Kappler. 1998. Detection of antigen-specific T cells with multi- 
valent soluble class II M H C covalent peptide complexes. Immunity. 8:675-682.

41. Boniface, J.J., J.D. R abinowitz, C. W ulfing, J. Hampl, Z. R eich, J.D. Altman, R .M. K antor, C. Beeson, H.M. M cC onnell, and M.M. Davis. 1998. Initiation of signal transduction through the $T$ cell receptor requires the multivalent engagement of peptide/ M H C ligands [published erratum at 9:891]. Immunity. 9:459-466.

42. Binder, T.A., D.L. Greiner, M. Grunnet, and I. Goldschneider. 1993. R elative susceptibility of SJL/J and B10.S mice to experimental allergic encephalomyelitis (EAE) is determined by the ability of prethymic cells in bone marrow to develop into EAE effector T cells. J. N euroimmunol. 42:23-32.

43. Binder, T.A., R .B. Clark, and I. Goldschneider. 1991. R elative susceptibility of SJL/J and B10.S mice to experimental allergic encephalomyelitis is correlated with high and low responsiveness to myelin basic protein. J. N euroimmunol. 35: 31-43.

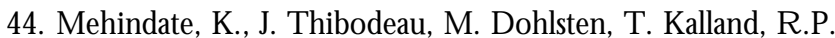
Sekaly, and W. M ourad. 1995. C ross-linking of major histocompatibility complex class II molecules by staphylococcal enterotoxin A superantigen is a requirement for inflammatory cytokine gene expression. J. Exp. M ed. 182:1573-1577.

45. Chang, J.T., E.M. Shevach, and B.J. Segal. 1999. R egulation of interleukin (IL)- 12 receptor $\beta 2$ subunit expression by endogenous IL-12: a critical step in the differentiation of pathogenic autoreactive T cells. J. Exp. M ed. 189:969-978.

46. Topalian, S.L., M.I. Gonzales, M. Parkhurst, Y.F. Li, S. Southwood, A. Sette, S.A. R osenberg, and P.F. R obbins. 1996. M elanoma-specific CD $4^{+} \mathrm{T}$ cells recognize nonmutated HLA-DR - restricted tyrosinase epitopes. J. Exp. M ed. 183:1965-1971. 